\title{
Risk factors for in-hospital mortality in premature infants with critical congenital heart disease
}

Jeonghee Shin, MD

Department of Pediatrics, Korea University Guro Hospital, Seoul, Korea

\section{Key message}

The incidence and mortality rates of critical congenital heart disease (CHD) are higher in preterm than in term infants. The risk factors for in-hospital mortality in premature infants with critical CHD are unclear. However, the mortality of preterm infants with critical CHD may be related to CHD complexity as well as gestational age, birth weight, the presence of prematurity-associated comorbidities, and the treatment itself.

Congenital heart disease (CHD) is among the most common congenital defects and is the leading cause of infant death in developed countries. It affects 1-2 per 100 live births, with approximately $25 \%$ of cases being critical CHD, ${ }^{1,2)}$ Critical CHD presents serious life-threatening conditions that require stabilization with medical treatment such as prostaglandin or cardiac surgery or interventional procedures within months after birth. ${ }^{3)}$ Critical CHD has a higher incidence in premature than term infants, and preterm birth itself is the main cause of newborn morbidity and mortality. There have been reports of increased mortality and morbidity in premature infants with $\mathrm{CHD},{ }^{4,5}$ Therefore, identifying the specific prognostic factors of preterm infants with critical CHD is expected to help identify treatment modality and timing.

The retrospective cohort single-center study conducted by Yoon et al. ${ }^{6}$ published in the current issue analyzed the risk factors for in-hospital mortality among premature infants with critical CHD. This is the first report in Korea to analyze use of the classification of Risk Adjustment for Congenital Heart Surgery (RACHS-1) according to CHD complexity or severity. Seventyeight premature infants were included in this study. Of them, 68 underwent cardiac surgery or intervention, 9 died before surgical treatment, and 1 was discharged without treatment.

The RACHS-1 was proposed as a classification system of the risk of in-hospital mortality according to surgery type used to treat $\mathrm{CHD}$ and has been used to study CHD-related risks. ${ }^{7)}$ However, since some cases of $\mathrm{CHD}$ are treated with interventional procedures rather than surgery, studies have analyzed a modified RACHS (m-RACHS) classified by diagnosis and gestational age of newborns as prognostic factors, including diseases treated through interventional procedures and surgery. ${ }^{5)}$ Since diseases not presented in the m-RACHS classification were included in the cohort of Yoon et al., $\left.{ }^{6}\right)$ the researchers further classified them to create an M-RACHS complexity classification and analyzed whether an M-RACHS with higher complexity (M-RACHS 5) was a risk factor for in-hospital death. In this study, risk factors for in-hospital mortality in premature infants with critical CHD were identified as independent risk factors such as very low birth weight, bronchopulmonary dysplasia (BPD), persistent pulmonary hypertension of the newborn (PPHN), and M-RACHS $\geq 5$ through a multivariate analysis. Factors such as postnatal age, postmenstrual age, weight at the time of treatment, and postbirth transfer were not associated with mortality in 68 patients who underwent treatment.

Medical conditions such as BPD or PPHN might be risk factors for outcome, but it was difficult to differentiate between them in this study. In the M-RACHS classification, critical CHD variants such as pulmonary atresia with intact ventricular septum, tricuspid atresia, and Ebstein anomaly were not included, which may limit the application of the new classification in clinical situations.

Several studies have reported on the risk factors for death of premature infants with critical CHD, but the results are inconsistent among different study designs. Nevertheless, premature infants reportedly showed a higher mortality rate than term infants when $\mathrm{CHD}$ was present, ${ }^{8)}$ while critical CHD was associated with significantly increased mortality rates in preterm infants ( $<32$-week gestational age or $<1,500$-g birth weight). ${ }^{9)}$ The complexity of CHD or the risk of surgery or intervention becomes a risk factor for mortality. ${ }^{10)}$ The optimal timing for intervention remains unclear due to the diversity of population characteristics. When technically possible, early primary repair is preferred, but delayed intervention in premature infants may enable weight gain in anticipation of subsequent repair. If surgery is performed when the infant has a body weight that can withstand cardiopulmonary bypass, surgical timing does not seem to be a risk factor for mortality. ${ }^{11)}$ Preterm infants with $\mathrm{CHD}$ more commonly develop $\mathrm{BPD}$ than those without $\mathrm{CHD}$ because of undergoing prolonged mechanical ventilation and developing congestive heart failure. ${ }^{12)}$

In conclusion, risk factors for in-hospital mortality in premature

Corresponding author: Jeonghee Shin, MD. Department of Pediatrics, Korea Universiy Guro Hospital, 148, Gurodong-ro, Guro-gu, Seoul 08308, Korea 凶E-mail: sourerkr@korea.ac.kr, https://orcid.org/0000-0003-3718-968X

Received: 24 March, 2020, Revised: 14 September, 2020, Accepted: 28 September, 2020

This is an open-access article distributed under the terms of the Creative Commons Attribution Non-Commercial License (http://creativecommons.org/licenses/bync/4.0/) which permits unrestricted non-commercial use, distribution, and reproduction in any medium, provided the original work is properly cited. Copyright (c) 2020 by The Korean Pediatric Society 
infants with critical CHD are unclear. However, characteristics such as gestational age, birth weight, CHD complexity, related medical conditions, and technical accessibility of the surgical approach for the patient could be risk factors for death and should be considered when determining surgical or interventional treatment.

\section{Conflicts of interest}

No potential conflict of interest relevant to this article was reported.

See the article "New modified version of the Risk Adjustment for Congenital Heart Surgery category and mortality in premature infants with critical congenital heart disease" via https:/doi. org/10.3345/cep.2019.01522.

\section{References}

1. Dolk H, Loane M, Garne E, European Surveillance of Congenital Anomalies Working G. Congenital heart defects in Europe: prevalence and perinatal mortality, 2000 to 2005. Circulation 2011;123:841-9.

2. Oster ME, Lee KA, Honein MA, Riehle-Colarusso T, Shin M, Correa A. Temporal trends in survival among infants with critical congenital heart defects. Pediatrics 2013;131:e1502-8.

3. Mahle WT, Newburger JW, Matherne GP, Smith FC, Hoke TR, Koppel $\mathrm{R}$, et al. Role of pulse oximetry in examining newborns for congenital heart disease. Circulation 2009;120:447-58.

4. Laas E, Lelong N, Acel PY, Bonnet D, Houyel L, Magny JF, et al. Impact of preterm birth on infant mortality for newborns with congenital heart difects: The EPICARD population-based cohort study. BMC Pediatrics
2017;17:124.

5. Steurer MA, Baer RJ, Keller RL, Oltman S, Chambers CD, Norton ME, et al. Gestational age and outcomes in critical congenital heart disease. Pediatrics 2017;140:e20170999.

6. Yoon YM, Bae SP, Kim YJ, Kwak JG, Kim WH, Song MK, et al. New modified version of the Risk Adjustment for Congenital Heart Surgery category and mortality in premature infants with critical congenital heart disease. Clin Exp Pediatr 2020;63:395-401.

7. Jenkins KJ, Gauvreau K, Newburger JW, Spray TL, Moller JH, Iezzoni LI. Consensus-based method for risk adjustment for surgery for congenital heart disease. J Thorac Cardiovasc Surg 2002;123:110-8.

8. Cheng HH, Almodovar MC, Laussen PC, Wypij D, Polito A, Brown DW, et al. Outcomes and risk factors for mortality in premature neonates with critical congenital heart disease. Pediatr Cardiol 2011;32:1139-46.

9. Norman M, Hakansson S, Kusuda S, Vento M, Lehtonen L, Reichman $\mathrm{B}$, et al. Neonatal outcomes in very preterm infants with severe congenital heart defects: an international cohort study. J Am Heart Assoc 2020; 9:e015369.

10. Abrishamchian R, Kanhai D, Zwets E, Nie L, Cardarelli M. Low birth weight or diagnosis, which is a higher risk?--A meta-analysis of observational studies. Eur J Cardiothorac Surg 2006;30:700-5.

11. Hickey EJ, Nosikova Y, Zhang H, Caldarone CA, Benson L, Redington A, et al. Very low-birth-weight infants with congenital cardiac lesions: is there merit in delaying intervention to permit growth and maturation? J Thorac Cardiovasc Surg 2012;143:126-36, 36 e1.

12. Polito A, Piga S, Cogo PE, Corchia C, Carnielli V, Da Fre M, et al. Increased morbidity and mortality in very preterm/VLBW infants with congenital heart disease. Intensive Care Med 2013;39:1104-12.

How to cite this article: Shin J. Risk factors for in-hospital mortality in premature infants with critical congenital heart diseasepatients? Clin Exp Pediatr 2020;63:391-2. https://doi. org/10.3345/cep.2020.00444 